although like nothing found in Egypt or elsewhere, appear to be exotic and show that the Nilotic usage of stone vessels wrought in decorative materials had taken root at Knossos in the late Neolithic phase.

Among other elements of Cretan culture showing affinities to the early culture of the Nile and of the indigenous inhabitants of the opposite Libyan coasts, are the large stone ossuaries in the beehive form of the Messara plain on the southern border of the island, contrasting with the rectangular habitations of Crete. Stone idols from Hagia Triada curiously recall those found in predynastic Egypt. They show the high head and pointed beard of the Nilotic race, and possibly passed to Crete from Libya. The Cretan mode of head-dress and the type of loin clothing show either a resemblance or a general analogy with that of the Libyans. The Libyan Delta goddess appears to have been, in part at least, incorporated in the Cretan mother goddess, as is shown in the form of bow, arrows, and shield which are the attributes of the former. In the stone ossuaries, the discovery of palettes of stone similar to those used by the predynastic Egyptians for antimony and malachite to adorn the person are peculiarly significant.

These striking correspondences in forms and usage, and especially in the contracted burials of the vaulted tombs of Messara, the dolichocephalic skulls, and the recurrence of foot-shaped amulets of stone, suggest a settlement of a proto-Libyan element in the southern foreland of Crete. These tombs are of a true beehive type, but they differ from the Mycenæan examples in their entrance system. They represent a sepulchral type which has a wide diffusion in the old Libyan region of North Africa. This proto-Libyan settlement became entirely assimilated in the Old Cretan population, but the engrafting of this artistic element on the indigenous island stock may well have contributed to the later bloom of Minoan culture.

At the conclusion of the lecture, the president of the Institute presented the Huxley Medal to Sir Arthur Evans.

\title{
The Flame Spectra of Carbon Monoxide and Water Gas.
}

TWO papers by Mr. F. R. Weston, recently published in the Proceedings of the Royal Society (A, vol. I09, I925, pp. I76-I86 and 523-526), embody the results of researches into the flame spectra of carbon monoxide, hydrogen, water gas, etc., which he has conducted at the Imperial College of Science and Technology under the joint supervision of Profs. W. A. Bone and A. Fowler. The object of the researches was to elucidate certain aspects of the combustion of carbon monoxide, and notably whether or not this gas interacts directly with oxygen in flames, a point which has been much disputed amongst chemists during the past forty years, but now seems to be in the way of being definitely cleared up by the spectroscope.

The spectrum of a flame of undiluted carbon monoxide burning in air (or oxygen) at atmospheric pressure is shown to consist of a banded radiation, extending from 5000 A.U. in the visible region to $2200 \AA$.U. far in the ultra-violet, upon which a continuous spectrum is superimposed. Both the banded and continuous parts of the spectrum, which are associated with the characteristic colour and actinic properties of a carbon monoxide flame, are most probably due to divect interactions between carbon monoxide and oxygen molecules in the flame, without any intervention of steam. At the same time, unless both the carbon monoxide and oxygen are previously dried before combustion, the spectrum shows some characteristic "steam lines," due to interactions between $\mathrm{CO}$ and $\mathrm{OH}_{2}$ molecules in the flame, which proceed simultaneousily with, and independently of, the $\mathrm{CO}$ and $\mathrm{O}_{2}$ interactions.

As the carbon monoxide in the burning gas was progressively replaced by hydrogen, both the banded and continuous parts of the spectrum rapidly faded away, until with an equimolecular (that is, $50 \mathrm{CO}+5 \mathrm{O} \mathrm{H}_{2}$ by volume) mixture of the two combustible gases (water gas) only "steam lines" remained visible in the spectrum, the characteristic CO-radiation and flame-colour having almost entirely disappeared.

When a flame of undiluted carbon dioxide was burnt (undried) in oxygen under reduced pressure, the banded part of the spectrum became more distinct and the continuous part less intense as the pressure was diminished; the "steam lines" were invariably present in the spectrograms. When a flame of carbon monoxide, previously dried by passage through strong sulphuric acid, was burnt at atmospheric pressure in oxygen, similarly dried, the "steam lines" in the resulting spectra had almost disappeared (they were only faintly visible), whereas the intensity of the continuous part of the spectrum remained undiminished.

The conclusion drawn from the experiments is that in the flame of pure (undried) carbon monoxide two sets of independent interactions occur simultaneously, namely: (a) direct interactions between carbon monoxide and oxygen, exciting radiations which give rise to the continuous and banded parts of the spectrum, and to the characteristic blue colour of the flame, and $(b)$ interactions between $\mathrm{CO}$ and $\mathrm{OH}_{2}$ molecules, which originate the "steam lines" in the spectrum. When hydrogen is gradually added to the burning gas the relative proportions of the firstnamed interactions diminish rather rapidly and proportionately more of the carbon monoxide is burnt by interaction with $\mathrm{OH}_{2}$-molecules, until when an equimolecular mixture of carbon monoxide and hydrogen is reached, the carbon monoxide-steam interactions occur to the practical exclusion of the carbon monoxide-oxygen interactions. These experiments have afforded the first clear evidence that in an ordinary carbon monoxide flame both sets of interactions are going on independently and simultaneously.

\section{School Natural History Societies.}

THE Marlborough College Natural History Society is interesting as a school institution which has had an unbroken existence since I864, when it was founded under the auspices of the then headmaster, later Dean Bradley of Westminster; it now issues its seventy-third printed report. Marlborough is situated in an unique position for this study, with some primeval forest in Savernake on one side and the open savannahs of the Downs on the other. Between the two runs the Kennett, here quite a small sluggish stream noted for its excellent trout-fishing, with beds of willows and water meadows by its sides. Near its head waters, from six to seven miles away, lie Silbury Hill and Avebury, the latter with its immense stone circles. The Downs show dolmens and tumuli, most of the latter probably of much later age, and there 